\title{
LOS ESTUDIOS ANDINOS Y LA ETNOHISTORIA EN LA UNIVERSIDAD DE BUENOS AIRES
}

\author{
ANDEAN STUDIES AND ETHNOHISTORY \\ AT THE UNIVERSITY OF BUENOS AIRES
}

\author{
Ana María Lorandi ${ }^{1}$
}

En memoria de Olivia Harris

\begin{abstract}
En este artículo me propongo reflexionar sobre lo realizado en etnohistoria del Noroeste argentino (NOA) cuando el interés por "lo andino" instalado por John Murra se encontraba en su apogeo y sus repercusiones en las riberas del Plata se pueden observar con mayor claridad, exponiendo los marcos teóricos y metodológicos utilizados. Finalizaré comentando los intentos de transpolar a nuestra región los modelos derivados de los estudios de frontera con el fin de señalar sus falencias y debilidades.
\end{abstract}

Palabras claves: etnohistoria del Noroeste Argentino, John Murra, etnohistoria andina, metodología.

In this article I set out to think about researches in Ethnohistory of the Argentina Northwest (NOA) as they were when interest in "lo andino" as urged by John Murra was at its apogee. Those studies' repercussions on the shores of the Río de la Plata allow us to observe with greater clarity the theoretical and methodological frames used. I will close by commenting on attempts of apply in our region models derived from the studies of borderlands, indicating to mistakes and weaknesses of this approach.

Key words: Argentina Northwest ethnohistory, John Murra, Andean ethnohistory, methodology.

La invitación de los editores de Chungara para participar en un volumen en homenaje a John Murra es una excelente oportunidad para marcar la influencia teórica y metodológica de este gran maestro en mis investigaciones personales y en las del equipo que formé en la Universidad de Buenos Aires, algunos de cuyos miembros se dispersaron en varias universidades del interior del país y del extranjero. Me permitiré reflexionar sobre lo realizado en etnohistoria del Noroeste argentino (NOA) cuando el interés por "lo andino" instalado por Murra se encontraba en su apogeo y sus repercusiones en las riberas del Plata se pueden observar con mayor claridad en la producción de la década de 1980, aunque se prolonga varios años más. Finalizaré comentando críticamente los intentos de aplicar a nuestra región los nuevos modelos derivados de los estudios de frontera.

Iniciamos las investigaciones en la década de 1980 cuando el concepto de "lo andino" presentaba una fuerte impronta esencialista. Fue concebido para otorgarle "identidad" a expresiones culturales tales como los mecanismos de obtención de recursos y la estructuración social, política y cosmogónica, rasgos con los cuales se marcaban las diferencias con el proceso mesoamericano. Este concepto, ahora cuestionado, integraba características concentradas en la zona serrana y altiplánica y minimizaba la gran variedad interna, incluso con la costa, pero sobre todo con las regiones más alejadas de ese núcleo que pivoteaba durante el Tawantinsuyo en torno al Cusco. Las diferencias entre ese centro y la periferia sur-meridional, advertidas a medida que avanzaban nuestras investigaciones, nos alentaron a preguntarnos si nuestros indígenas también podían ser considerados andinos o si, como nos encontrábamos "en las fronteras del Imperio", podíamos aplicar las categorías y clasificaciones utilizadas para los Andes Centrales y Meridionales.

Planteamos esas diferencias como resultado de un encadenamiento de poblaciones en su doble relación con su medio ambiente serrano -que incluía la Puna y valles- y con las llanuras orientales. Teniendo en claro que nuestros referentes eran los estudios andinos, interesa discutir en este artículo el proceso de construcción del sujeto de nuestras investigaciones, buscando la adaptación de las categorías y prácticas sociales y políticas a las realidades que descubríamos en las fuentes.

\footnotetext{
1 Universidad de Buenos Aires, Consejo Nacional de Investigaciones Científicas y Técnicas. Financiación: Secretaría de Investigación de la Universidad de Buenos Aires, UBACYT. Facultad de Filosofía y Letras, Puan 480, of. 405 y 413, 1080 Ciudad Autónoma de Buenos Aires, Argentina. anamarialorandi@gmail.com
} 
Mi interés por los estudios andinos partió desde la arqueología y como resultado de la actividad docente escribí un primer trabajo comparando investigaciones de John Murra, Augusto Cardich y Pierre Duviols (Lorandi 1977, 1978). A partir de las excavaciones en el centro incaico Potrero Chaquiago de la provincia de Catamarca, nos interesamos por el traslado de mitimaes originarios de las llanuras tucumano-santiagueñas combinando datos arqueológicos con la escasa información que ofrecían las crónicas y los documentos locales sobre la expansión del Tawantinsuyu en nuestra región (Lorandi 1983; Lorandi et al. 1991). El enfoque respondía al impulso que Murra le otorgaba a la colaboración entre arqueología y etnohistoria (Morris y Thompson 1985; Hyslop 1990).

Estas experiencias me fueron familiarizando con las fuentes locales y me atreví a explorar el lugar simbólico y político que ocupaba el Noroeste Argentino (NOA) dentro del espacio andino meridional durante el período imperial, recurriendo en buena medida a la información y a las categorías elaboradas por Thérèse Bouysse-Cassagne (1978) para la región altiplánica (Lorandi $1980^{1}$ ). Más adelante retomaremos este tema.

Con estos trabajos fui ingresando con mayor asiduidad a la problemática andina, manteniendo una frecuente correspondencia y contactos personales con Murra y con los colegas americanos y europeos que se ocupaban de los Andes. Desde 1984 y con la colaboración de Mercedes del Río y de Ana María Presta, pude iniciar la formación del primer equipo de Etnohistoria en la Universidad de Buenos Aires. Tuvimos el declarado propósito de reinstalar esta disciplina que, por diversas razones -debates teóricos y/o competencias académicas-, había caído en descrédito en nuestro país. Simultáneamente creamos una nueva cátedra para discutir por primera vez la bibliografía etnohistórica sobre México y los Andes.

\section{El Tucumán en los Andes Meridionales}

A medida que el equipo incorporó nuevos miembros se ampliaron los intereses de investigación sobre las provincias del noroeste, mientras Mercedes del Río y Ana María Presta lo hacían sobre poblaciones altiplánicas o en los valles mesotérmicos hoy bolivianos. Rápidamente nos dimos cuenta que las fuentes locales no permitían trasladar al NOA las categorías que se descubrían y discutían para los Andes Centrales y que resultaría difícil abordar algunos de los temas que ocupaban la atención de nuestros colegas. Un ejemplo muy simple: no disponíamos para el noroeste de Visitas que a John Murra $(1967,1975,2000)$ le permitieron descubrir las prácticas del control de múltiples pisos ecológicos, o la información estudiada por del Río y Presta para seguir con detalle los cambios en la estructura política y económica de los que en esa época se consideraban los grandes señoríos del altiplano y los grupos vallunos de la frontera oriental (del Río 1989; 1990; del Río y Presta 1984; Presta 1989 y Presta y del Río 1993). Las diferencias en el grado de complejidad de la organización política de los habitantes del noroeste, consistentes en cacicazgos de rango intermedio, centros incaicos de menor envergadura y la ausencia de recursos mineros de importancia fueron factores rápidamente comprendidos por los conquistadores hispanos que adaptaron las instituciones coloniales a esa nueva realidad. Por ejemplo, para los Andes Centrales, Murra (1978) insistía en marcar la diferencia entre el modelo tributario andino, basado en las prestaciones rotativas en beneficio de los señores locales y del estado Inca por un lado, y el tributo colonial en bienes o en dinero por el otro. Pues bien, nuestras investigaciones pusieron en evidencia que el tributo en el Tucumán colonial consistió en el llamado sistema de servicio personal que perduró hasta el siglo XVIII y afectó la cohesión de las comunidades por no estar obligadas a reunir colectivamente el monto de la tasa bajo la autoridad y control de un curaca o cacique, situación que a veces favoreció en las zonas centro-meridionales la creación artificial de colectivos indígenas que alcanzaron cuerpo de comunidad. Primero sugerimos que esta diferencia obedecía a la escasez de excedentes; posteriormente preferimos atribuirlo a cacicazgos menos jerarquizados y demográficamente reducidos. Lo cierto es que el tributo de servicio personal provocó -en algunas zonas y durante más de un siglo- un mayor grado de desestructuración de las comunidades indígenas, afectadas por traslados y dispersión de la población (Lorandi 1988). Posteriormente estas conclusiones se matizaron, reconociendo que las prácticas del sector septentrional de la región -Puna y Quebrada de Humahuaca- se asemejaban más a las altiplánicas de la Bolivia actual que a las del centro de la Provincia del Tucumán (Zanolli y Lorandi 1995).

Durante el período 1984-1987 se pulieron las herramientas para interpretar la discursividad de 
los textos coloniales, considerando sus objetivos y contextos de producción y a los destinatarios de los mismos. Se atendió a lo dicho y a lo no dicho -a los silencios- tanto en las fuentes como en la historiografía, buscando descubrir sus sentidos a partir de una minuciosa reconstrucción de la matriz de producción de los discursos.

Se focalizó, por un lado, en la identificación sociocultural de las comunidades indígenas y en su dinámica interna, así como en sus transformaciones por acción directa de los estados incaico y español. Por el otro, se analizaron las estrategias y representaciones indígenas tendientes a limitar, contrarrestar o explotar la coerción económica y extraeconómica de los sectores dominantes en cada coyuntura histórica. La doble perspectiva permitió reconstruir entramados complejos de prácticas y representaciones donde se observaban múltiples niveles de articulación y contradicción; de cambio y de continuidad (Boixadós 1993; Schaposchnik 1995). En los años posteriores estas líneas no se han abandonado, por el contrario, se han reforzado con nuevos temas, aunque en la mayor parte de los casos ampliando el lapso histórico hasta finales del período colonial, siguiendo en esto la tendencia prevaleciente en las investigaciones sobre Perú y Bolivia. Una síntesis de nuestros trabajos durante esta etapa se puede encontrar en los dos volúmenes compilados por Lorandi en 1997, bajo el título El Tucumán Colonial y Charcas pero en su mayoría publicados con anterioridad. Se debe señalar además que, a pesar de la ampliación de los objetivos y gracias a la incorporación de nuevos integrantes al equipo, el interés por los estudios étnicos no se ha abandonado, incluso se enriquecieron al combinar trabajo de campo etnográfico y compulsa de fuentes (Rodríguez 2008; Sendón 2003) ${ }^{2}$.

\section{La Adaptación de las Categorías y Clasificaciones Andinas al Espacio Local}

El uso de las categorías y las clasificaciones exigen una atención especial cuando se las aplica de una región a otra. Murra ya había planteado algunas advertencias sobre este problema y los recientes estudios sobre la metodología y la epistemología de la generalización (Passeron y Revel 2005) advierten sobre sus posibilidades y límites. Evidentemente temerosos de sobreinterpretar los datos contenidos en las fuentes pusimos especial atención y prudencia para tratar de entender con qué tipo de sociedades estábamos trabajando y sobre todo qué tipo de colonización se estaba instalando en esta región. Por lo tanto debíamos afinar la metodología, considerar la distancia con respecto a los Andes Centrales, evaluar las particularidades ecológicas y las características socioculturales de las poblaciones que rodeaban la zona serrana $y$, vinculada con ambos aspectos, la forma que adquirió la estructura social de la región.

\section{El desafío metodológico}

Interesados en estudiar la organización interna -social y simbólica- y la estructura de autoridad de las configuraciones políticas del noroeste argentino nos plantearon las siguientes preguntas: ¿Encontraríamos aquí algo semejante a los grandes señoríos aymaras? ¿Existía una estructura binaria? ¿La obtención de recursos reproducía el "modelo de control vertical"? Rápidamente comprendimos que sin un mejor conocimiento de las fuentes locales y de los datos empíricos que ellas nos aportaran era imposible utilizar modelos construidos a partir de realidades diferentes. Por lo tanto, era necesario estudiar las características de las fuentes locales, clasificarlas de modo de no meter en la misma bolsa los datos extraídos de distintos tipos de documentos. No tiene el mismo valor testimonial una carta, una probanza de méritos, los partes de guerra, o los informes oficiales (Lorandi y Bunster 1987-1988; Schaposchnik 1991). Con este recurso tratamos de descubrir las voces de los indígenas detrás de la multisemia de las categorías empleadas en la documentación y de las variadas capas de mediatización de los actores europeos, los únicos que nos ofrecen información.

Los españoles reconocieron las particularidades que se presentaban en estas tierras. Por ejemplo, el concepto de ayllu, escasamente usado, fue abandonado y optaron por el término neutro de parcialidad aunque, con felices excepciones, se abstienen de indicar si eran parte de una unidad mayor. Con parcialidad hacían referencia tanto a grandes grupos (internamente subdivididos y jerarquizados) como a jefaturas integradas por uno o dos linajes.

Fue importante distinguir entre situaciones de proceso de conquista y plena colonización. Si bien regresaremos sobre este tema, adelantamos algunos ejercicios realizados en esos primeros años. Analizando cédulas de encomiendas, Boixadós (1992) distingue dos tipos de fórmulas de orden 
contrapuesto: (1) "empleo reiterado de fórmulas que implican consenso acerca de su significado formal" tales como el pueblo tal y sus anexos, o el cacique tal con los pueblos que tiene o tuviese, y (2) fórmulas que encierran en sí mismas un "contenido de significación real", o sea que se adecuan a las condiciones efectivamente observadas. Este ejemplo nos permite recordar la importancia de los juicios por encomiendas para la dilucidación de las disputas por las identificaciones étnicas (Boixadós 1993), situación que solo se produce bajo plena colonización y no, como discutiremos más adelante, en el momento de transición cuando la documentación aporta información general y menos controvertida.

Simultáneamente la arqueología resultaba fundamental para aproximarnos al período prehispánico, considerando que la documentación histórica proviene de la visión española por falta de informantes nativos que se refieran a esa época.

Frente a esta situación debimos preguntarnos ¿en qué medida las categorías y clasificaciones étnico-culturales vertidas en esos papeles tempranos reflejan la realidad ya sea pre o post incaica?, o ifueron asignadas por los españoles para optimizar el control y la dominación? Optamos por la prudencia, planteando preguntas e historizamos el sentido de cada palabra considerando que existían organizaciones políticas con un cierto grado de jerarquización interna, acotados derechos a las tierras, a los recursos y a los lugares de culto y que cada unidad política defendía sus propios límites o podía intentar invadir los ajenos. Hay muchas pruebas (como los pueblos instalados en alturas inaccesibles o algunos amurallados) de frecuentes conflictos interétnicos por el control de recursos o predominio político. Conflictos que no constituían una excepción durante el período de los "Desarrollos Regionales", equivalente al "Intermedio Tardío" en los Andes Centrales.

En 1997 revisando nuestros trabajos anteriores decíamos lo siguiente

[...] en realidad, las aparentes diferencias entre los señoríos del norte y las jefaturas menos estructuradas del sur, encierran una problemática que tiene todavía sus grandes interrogantes. La mayor dificultad que hay que vencer $[. .$.$] se vincula con las alteracio-$ nes que produjo el Estado Inca en el mapa étnico y político a largo del Tawantinsuyu.
[Por ello] ha sido necesario instrumentar diversos recursos metodológicos que nos permitieran descubrir las alteraciones incaicas, para no incurrir en el error de aceptar como originales las organizaciones políticas que estaban vigentes al momento de la conquista española. [...] De modo que, como resultado de estas dos intervenciones, aún para la información más temprana, el investigador que pretende recuperar el estado de las agrupaciones políticas tal como pudieron estar estructuradas antes de la conquista inca, debe pasar todos los datos por un doble filtro de confiabilidad (Lorandi 1997:19).

Nos preocupaba no confundir una configuración posiblemente manipulada por los incas con la situación previa a dicha intervención.

Es así que, en ese mismo capítulo agregamos

Por otra parte, fue necesario comprender que si nos proponíamos como objetivo excluyente el de descubrir el estado "prístino" de las agrupaciones étnicas nos encontraríamos rápidamente en un callejón sin salida. [...]. En el caso peruano, existe una abundante literatura iniciada por Fernando Fuenzalida (1970) [...] que destaca la matriz colonial de las comunidades andinas, aunque éstas hundieran sus raíces en el pasado prehispánico [...]. Si lo que nos interesaba era estudiar las transformaciones sociales a lo largo del proceso colonial, debíamos aceptar la validez de cualquier "punto cero" [artificial] para iniciar nuestras investigaciones. O sea, partir de la estructura sociopolítica que podíamos recuperar en el momento más antiguo posible, de acuerdo con lo que nos permitía la documentación (Lorandi 1997:19).

Como se trataba de investigaciones de un equipo abordamos simultáneamente varias problemáticas sin perder de vista la unidad cultural de la región. Aunque existían matices, analizamos cuidadosamente las categorías y clasificaciones utilizadas y las comparábamos con la de los Andes Centrales historizando nuestras fuentes al compás del avance de la colonización en sus variables espaciales, temporales y políticas. 


\section{El concepto de frontera}

En los primeros trabajos nos preguntamos en qué sentido el Noroeste puede ser incluido en la categoría de espacio fronterizo, con respecto al Estado inca y también a sus vecinos de los llanos orientales. El control incaico de las poblaciones del NOA fue parcialmente diferente al de los Andes Centrales, pero eso también sucedía en el extremo septentrional del Imperio. Tuvieron que enfrentar cacicatos más segmentados que ofrecieron prolongada resistencia como en los valles calchaquíes de modo que se vieron obligados a construir muchos centros estatales e instalar miles de mitimaes (Lorandi 1998 [1988]) provenientes del Perú o del altiplano y de las yungas orientales (Tucumán y Santiago del Estero). Estos últimos participaron de la construcción de lo que ahora se denomina como "lógica mestiza" (Amselle 1999 [1990]), compuesta de elementos andinos y chaqueños. A esto se suma un doble clientelismo en tanto fueron los encargados de defender esa frontera de los ataques de lules y chiriguanos. Se trató de los juríes, categoría cultural con la que los aymaras identificaban a los habitantes de las yungas meridionales porque se vestían con plumas de suris (suris-juríes) ${ }^{3}$, se insertaron en los asentamientos estatales y colaboraron también en el control de la población serrana local. Mitaron bajo supervisión incaica, lo que puede explicar que el quichua se hablara en las llanuras santiagueñas tan temprano como en 1580 según el primer misionero jesuita, el padre Bárcena, que las visitó cuando la colonización recién comenzaba. Basados en nuestras investigaciones arqueológicas en los valles serranos y las previas realizadas en las llanuras de Santiago del Estero (1965-1975) pudimos emprender el estudio del sector meridional de la frontera oriental (Lorandi 1980) observando que se producían los mismos procesos de doble clientelismo y doble circulación simbólica, política y económica que pocos años después describirían France Marie Renard-Cassevitz, Thierry Saignes y Christine Taylor (1986: I) para los sectores septentrional y central de los Antis. En ambas investigaciones la frontera fue concebida como un espacio de intermediación donde se configuran mestizajes culturales sin que las poblaciones marginales perdieran su autonomía política. Por lo tanto, se trata de una forma de interpretar la frontera que ya se estaba desarrollando en los estudios andinos desde la década del ochenta, pero que se aplicaba a las relaciones entabladas entre sociedades que tenían diferentes patrones culturales.

Estas investigaciones nos permitieron obtener una primera imagen de la situación prevaleciente en el NOA hasta la invasión hispana y evaluar posteriormente el comportamiento adoptado para enfrentar la nueva realidad. Retomaremos el tema en el próximo acápite.

\section{El proceso colonial y las identificaciones étnicas: ¿identidades impuestas? ${ }^{4}$}

La conquista y colonización del NOA se prolongó a lo largo de la segunda mitad del siglo XVI. Se inicia con la fundación de Barco en 1550 y culmina, tras muchísimas dificultades, con Todos los Santos de la Nueva Rioja en 1590 y San Salvador de Jujuy en 1591, con la excepción de los valles calchaquíes que persistieron en su autonomía hasta 1665 . Por razones de espacio optamos por referirnos a las investigaciones sobre las poblaciones calchaquíes, incluyendo metodología, organización sociocultural y relaciones interétnicas.

Los valles calchaquíes consisten en dos valles interconectados, de aproximadamente $300 \mathrm{~km}$ de largo en sentido norte sur y que albergaban una población multiétnica de más de 20.000 almas en 1659 , disponiendo de ricas tierras irrigadas natural y artificialmente. Habitaban en grandes pueblos conglomerados y disfrutaban de uno de los más altos niveles culturales de la región que, con sus particularidades, puede ser considerado un patrón andino. En este contexto, los valles calchaquíes se constituyeron en una "frontera de colonización" interna, aunque en este caso preferimos utilizar el concepto de "límite" como lo explicaremos más adelante. Entablando confederaciones entre cacicazgos, los calchaquíes ${ }^{5}$ impidieron durante 120 años la ocupación de sus territorios y preservaron su autonomía política y cultural aunque manteniendo relaciones inestables con los españoles instalados en el resto del Tucumán. Algunos grupos (los pulares del sector septentrional de los valles) alternaron servicios con resistencia -a veces violenta y otras elusivas- pero el resto de los cacicazgos no abandonó su actitud defensiva. No se observaron grandes diferencias en el patrón cultural entre los distintos sectores del valle excepto en algunas manifestaciones simbólicas como la alfarería por ejemplo.

Ahora bien, la hostilidad no significaba aislamiento cultural, sino preservación de la autonomía 
en el control cultural (Bonfil Batalla 1992) durante el largo intermedio transcurrido entre la llegada de los españoles al NOA y la efectiva colonización a finales del siglo XVII. La amplitud de la resistencia que presentaron todos sus pobladores provocó la dura represión española cuando lograron dominarlos: en su mayor parte fueron desnaturalizados, incluso los pulares, que por cortos períodos fueron sus aliados.

Nuestra investigación (Lorandi y Boixadós 1987-1988) se inició analizando los partes de guerra del gobernador Alonso de Mercado y Villacorta durante la campaña de 1659 y la contrastamos posteriormente con fuentes producidas desde la época de las primeras entradas de Diego de Almagro en 1536 y de Diego de Rojas en 1545, haciendo un corte cronológico que comprendía desde la ocupación incaica (calculada en torno a 1450 o 1480) hasta la derrota definitiva en 1665 . De esa manera pudimos percibir que la ausencia de un proceso de colonización con ocupación efectiva del territorio favoreció que los cambios culturales, cuando se produjeron, quedaran bajo el control de las comunidades. Bonfil Batalla (1992:116) define el "control cultural" como el "sistema según el cual se ejerce la capacidad social de decisión sobre los elementos culturales" entendido por la capacidad de "mantener la vida cotidiana, satisfacer necesidades, definir y solventar problemas, formular y tratar de cumplir aspiraciones". Sin duda la larga interacción, aunque fuera en su mayor parte a la distancia, de los calchaquíes con los españoles de los territorios colonizados les permitió incorporar elementos ajenos -el trigo y uso limitado del caballo, por ejemploy aprender a prever las acciones de sus enemigos (conocimiento del otro), pero las fuentes no revelan mayores cambios culturales entre lo observado durante las primeras "entradas" españolas y los de la campaña de Mercado en 1659. En todo caso fueron de menor envergadura. Tampoco se produjeron movimientos significativos de población ${ }^{6}$. Dado que la conquista no se hizo efectiva durante ese lapso, podemos considerar que se trata de un período transicional entre las primeras "entradas" y la plena colonización.

Para comprender este proceso podemos remitirnos a lo que Gonzalo Lamana (2008:14) escribe en relación con la conquista del Perú. En la transición entre el contacto y la dominación (que puede prolongarse más de lo generalmente aceptado) las configuraciones de sentido y de poder son frágiles. Si se toman sin crítica situacional los relatos oficiales de los conquistadores es claro que revelan el esfuerzo por mantener al nativo en posición subalterna a fin de justificar su intento de dominación. Estas prácticas se generalizan en Occidente a partir del siglo XVI y persisten en las diversas formas de neocolonialismo, donde es visible la tendencia a "restar capacidad de agencia a los Otros" (Lamana 2008:16).

De estos comentarios se desprende que no se deben confundir clasificaciones teñidas de objetivos políticos y regidas por principios axiológicos -salvaje vs civilizado- con identificaciones de grupos que eran imprescindibles para conocer con quienes se interactuaba, sobre todo cuando el proceso de conquista estaba inacabado o, como Lamana (2008) tituló su libro, en una situación de Domination without Dominance. Recordemos, además, que los investigadores del mundo andino advirtieron hace muchos años sobre la "colonización" de las categorías utilizadas para clasificar a la sociedad indígena (Guevara Gil y Salomon 1996; Wachtel 1997), revisión metodológica que continúa en la actualidad (Arkush 2009).

Un reciente artículo de Guillaume Boccara (2005), "Nuevos mundos en las fronteras del Nuevo Mundo", plantea como una novedad las precauciones que deben considerarse al analizar los discursos coloniales y republicanos con el objeto de "descongelar" las etnicidades y las diferenciaciones legadas por la sociedad occidental dominante y que en su opinión han sido adoptadas sin crítica por los etnohistoriadores y antropólogos, desconociendo que parte de los comportamientos que ellos rescatan responden en realidad a "lógicas mestizas" que se desarrollaron a raíz de los contactos interétnicos.

En un artículo reciente de Lorandi y Boixadós (2009) han discutido esos conceptos y modelos que Christophe Giudicelli (2007) aplica a los valles calchaquíes, sin apreciar las diferentes situaciones en que se desenvuelven las relaciones entre esos nativos y los españoles, minimizando los cambios que pudo provocar la ocupación inca de la región y atribuyendo las clasificaciones y el "encasillamiento del espacio" a los agentes coloniales. Confunde los límites que rodean los valles calchaquíes con el middle ground de los estudios de frontera y recurre al linguistic turn asumiendo "la realidad como un fenómeno constituido por y en el lenguaje" (Forte y Silva Prada 2006:9).

La lectura de los artículos de Boccara y Giudicelli incentivó reflexiones sobre nuestros propios trabajos 
y nos condujeron a preguntarnos si habíamos operado en la forma en la que ellos sugieren. La primera conclusión es que nunca hicimos un análisis en la larga duración con el objetivo de seguir desde la conquista hasta la república los procesos de etnogénesis y mestizaje cultural. Por el contrario, casi siempre trabajamos con cortes sincrónicos, por períodos muy cortos y en problemáticas relativamente acotadas, de manera de controlar las categorizaciones en uso en cada uno de ellos. En los trabajos de nuestro equipo desde la década de 1980 hasta el presente se constata la cuidadosa disecación de los discursos coloniales y las zonas como la Puna consideradas por los españoles como fronteras de guerra fueron también evaluadas (Zanolli 2005), aunque siempre distinguiendo las situaciones de conquista de las de plena colonización.

Por ello la otra pregunta que emerge de la lectura de estos artículos posmodernos es si es posible meter en la misma bolsa todos los procesos de conquista sin evaluar las características de cada conjunto social y sobre todo el "clientelismo con doble dependencia" según lo calificaron Renard-Cassevitz y Saignes (1986 I:57). Pero cuando no se produjo esta doble dependencia ni salvo el corto lapso (un año) durante el cual los indios pulares colaboraron con los españoles a cambio de reducción tributaria, los comportamientos de los calchaquíes en general no parecen haber respondido a esas "lógicas mestizas", por lo menos con la misma intensidad ni, lo más importante, con las mismas consecuencias.

Los valles calchaquíes resistieron primero la ocupación incaica, aunque fueron finalmente incorporados al Tawantinsuyu, y luego esa experiencia les sirvió para coordinar esfuerzos e impedir el avance y la colonización hispana. La relación con ambos estados nos obligó a preguntarnos sobre la naturaleza de la estructura política pre inca de los calchaquíes o si se constituyeron como un solo sujeto histórico a raíz de los conflictos con los estados inca y español. Sosteníamos que la experiencia histórica "admite transformaciones que dan paso a sucesivos mecanismos de adaptación ante una realidad siempre cambiante. En esta perspectiva, tradición y cambio no son elementos contradictorios sino convergentes" (Lorandi y Boixadós 1987-1988:264). En suma, nos preocupaba la dimensión cultural -manifestada en lo político, en lo simbólico y en las obras materiales de estas poblaciones-que había permitido identificar un sujeto históricamente construido tanto desde la arqueología cuanto desde la documentación legada por los hispanos, pero cuya estructuración y dinámica inter o intraétnica nos aparecía como confusa, cuando no contradictoria. Por ello estuvimos alertas al peligro de construir un "sujeto teórico que, por supuesto, no debemos confundir con la realidad, sino sólo utilizarlo como una categoría heurística" (Lorandi y Boixadós 1997:264).

Revisando nuestros textos encontramos que, efectivamente, utilizamos un paralelismo vigente en la época entre el concepto de grupo étnico y jefatura política. La existencia de los grandes señoríos (como los "reinos" de los que hablaba Murra) es actualmente sometida a críticas que muestran que fueron producto de negociaciones políticas y de sentido entre los indígenas y el Cusco primero y con los españoles después. Elizabeth Arkush (2009), en su estudio sobre los pukaraes del Collao sostiene que no existen evidencias arqueológicas de la existencia de un "reino" o "señorío" unificado anterior al Tawantinsuyu y extiende su interpretación a los restantes señoríos aymaras, hipótesis que está siendo discutida en este momento. Terence D'Altroy (1978) lo ha planteado para el caso de los Wankas en el Perú. En el NOA y en particular en Calchaquí visualizamos algunos aspectos que sugerían una reorganización incaica del espacio y posiblemente un reordenamiento de las configuraciones políticas, al menos en la zona $\operatorname{pular}^{7}$ y en Tolombón.

El problema que ahora visualizamos es la asimilación, que en ese momento establecimos, entre grupo étnico -concebido para identificar una población que comparte prácticas y creencias culturales-con una definida estructura política. Los investigadores tuvimos la tendencia a considerar que las identidades y organizaciones reflejadas en la documentación colonial, como las visitas coloniales por ejemplo, reproducían objetivamente la realidad. Como lo expresan Guevara Gil y Salomon (1996) es necesario distinguir entre lo "hallado" y lo "creado por decreto". Según Wachtel (1997) lo que a veces se ha considerado como identidades étnicas son -O fueron-identidades colectivas, construidas a partir de décadas o siglos de convivencia colonial.

Con estas citas quiero insistir en que las identificaciones étnicas teñidas por la acción de los agentes coloniales habían sido reconocidas en los trabajos andinos desde hace más de diez años y que la existencia de relaciones de clientelismo en doble sentido con las poblaciones de frontera-aclaremos, fronteras ecológicas y culturales-fue señalada por Renard-Cassevitz y Saignes (1986: I) desde hace 
más de veinte años. Por eso me parece interesante volver a referirme a los procedimientos que utilizamos en la década de 1980 cuando iniciamos las investigaciones sobre los valles calchaquíes.

Para sortear las dificultades que planteaban las fuentes Lorandi y Boixadós recurrieron a los criterios interaccionistas propuestos por Fréderick Barth (1979) que permitía trabajar con la autoadscripción (la menos frecuente en las fuentes) y la adscripción por los otros, distinguiendo las de los españoles de las de los indígenas. Siguiendo a Barth distinguimos por un lado los signos diacríticos culturales con los pocos datos disponibles, y las orientaciones de valores básicos: normas de moralidad y excelencia por la que se juzga su actuación-considerando que estos rasgos no son inmutables- para los cuales resultaron fecundos los partes de guerra del gobernador Mercado y Villacorta durante la campaña de 1659. Día a día Mercado consignaba los sucesos de la jornada, identificando a los grupos con los que había combatido, sus tácticas bélicas, la distancia entre ellos, la cantidad de pueblos que respondían a la autoridad de un determinado cacique y otros datos similares. La lectura atenta del extenso expediente ${ }^{8}$ permite distinguir la amplitud y localización de cada jefatura y evitar las trampas de las "identidades impuestas". Esta información contrastada con otras de distintas épocas, origen y propósitos (cartas, probanzas de mérito, cédulas de encomiendas) nos permitió reconstruir diferencias, visualizar las causas de determinados comportamientos o identificar descendientes de antiguos mitimaes incaicos o de "advenedizos" que se habían refugiado en el valle para escapar del control colonial. De hecho, los partes de guerra contienen discursos muy diferentes al de una crónica, de una carta o un informe al rey pues se rigen por otras fórmulas y valores. Como lo afirman Guevara Gil y Salomon (1996:33) , "es vital no separar el contenido "procesal" del "sustantivo", tratando de no separar información "etnográfica de las matrices documentales que la contienen". Advierten así de los peligros de considerar como prehispánicas a las organizaciones políticas tal como aparecen en las visitas coloniales. Pero la observación es igualmente útil si se procede a la inversa: tomar la información producida durante un proceso de conquista como si fuera consecuencia de actos efectivos de dominación y control.

En suma, revisando la "historicidad" de nuestra investigación recordamos que la primera tarea consistió en tomar "una fotografía" de la organización política y de la distribución espacial de las poblaciones de los valles calchaquíes teniendo como telón de fondo la información aportada por el gobernador Mercado y Villacorta en 1659. A partir de ese punto realizamos una historia regresiva tal como lo efectuara Wachtel (1997) inspirándose en Marc Bloch, con la compulsa de documentación más temprana, que nos permitiera evaluar cuáles eran los límites aceptables para esa proyección retrospectiva. Encontramos que debíamos considerar el "umbral" de la ocupación incaica en la zona y sugerir, cuando los datos arqueológicos lo permitieran, cuál pudo ser la situación previa.

\section{Conclusión}

El repaso de los marcos teóricos y metodológicos utilizados a partir del inicio de nuestras investigaciones en 1980 pretende mostrar los procedimientos puestos en juego para abordar el estudio de una región cuyas características socioculturales aparecían hasta ese momento de una manera confusa. Lo mismo puede decirse de los mecanismos de inserción de la sociedad indígena en los sistemas estatales incaico y español. Esta reflexión retrospectiva ha sido contrastada con un trabajo reciente cuyo enfoque proviene de realidades socioeconómicas y culturales diferentes a las andinas. Cuando comenzamos carecíamos de antecedentes locales sobre los procesos que afectaron a la sociedad indígena del NOA desde la perspectiva renovada que se había inaugurado con los aportes de John Murra. Por eso marchamos con pie de plomo, tanteando el terreno para evitar pisar alguna "mina” enterrada que nos hiciera volar por los aires. Leíamos cuanto artículo o libro se producía sobre los Andes, estuvimos en permanente contacto con los especialistas y procedimos con total minuciosidad en el análisis de las fuentes locales.

La principal dificultad consistió en evitar aplicar los modelos propuestos por Murra sin contrastarlos con las realidades que estábamos investigando. Su influencia para abordar los estudios andinos desde la perspectiva antropológica fue esencial para orientar nuestro propio camino, pero muy distintos hubiera sido forzar la información para adecuarla a dichos modelos. Lo que Murra nos enseñó fue a renovar nuestra forma de leer las fuentes, a respetar a nuestros sujetos y a considerarlos como agentes activos así como la continuidad entre lo preincaico y lo incaico. Lo que Murra enseña, sustancialmente, 
es a sacar de la pasividad a millones de personas que poblaban este gran Continente, actitud que conservaron también durante la colonia.

Por eso considero incorrecto sostener que las identificaciones étnicas fueron impuestas principalmente bajo el imperativo español de controlar y dominar y que es muy difícil recuperar las identidades previas a la conquista. De esa manera la agencia indígena se anula, o se la minimiza, poniendo en primer plano la manipulación española de las identidades al punto de transformar a los conquistadores en especie de titiriteros. Esto nos conduce a nuevas reflexiones metodológicas.

Es necesario historizar las fuentes en sus múltiples aspectos: el momento cronológico de producción en relación con el proceso de conquista y colonización, la identificación social y política de los autores de los documentos y de sus objetivos pero, sobre todo, conocer a fondo el medio ambiente y las características de las sociedades involucradas y de las interrelaciones que se entablaron entre ellos. Sin estas precauciones el análisis de la producción escrituraria española puede conducir a falsas conclusiones. Por todo ello me pareció interesante reflexionar sobre la forma en que nosotros procedimos en las investigaciones sobre los Andes argentinos.

Las problemáticas que se plantean estudiando a otros tipos de sociedades pueden siempre ofrecer conceptualizaciones útiles y enriquecedoras, pero sus traspolaciones deben ser efectuadas mediante un estricto control metodológico, cuyo basamento se encuentra en la correcta evaluación de la información empírica. En las ciencias sociales y en la historia no hay método ni teoría de utilidad universal. Sólo algunos conceptos muy generales, aquellos que se refieren a comportamientos básicos de la humanidad, pueden aplicarse en forma indistinta para cualquier sociedad y aún esto podría ser cuestionado.

Al señalar la importancia de la empiria no estoy proponiendo un método inductivo, pero los modelos son modelos y no realidades; sirven para orientar pero si se los aplica mecánicamente no producen aportes de valor. Para confirmar este punto de vista quiero citar un párrafo escrito en 1997 advirtiendo sobre los riesgos de la traspolación de los modelos altiplánicos a nuestra región

Los modelos -aunque parezca una tautologíasólo deben tomarse como tales. La estructura que presenta Tristan Platt para los Machas (1978b:1083) no puede ser generalizada sin aplicar previamente controles empíricos locales. Caso contrario se estarían ignorando las transformaciones históricas de las sociedades que demuestran que la realidad suele ser más variada y dinámica de lo teóricamente esperado (Lorandi 1997:27).

No obstante, en contextos relativamente similares como el citado es posible encontrar rasgos comunes que permitan establecer generalizaciones, siempre que se admitan ciertos grados de variabilidad. En nuestro caso reforzar la convicción de que las poblaciones del NOA pueden ser incorporadas sin reservas al gran espacio andino.

Respetar el modelo metodológico que en ese momento heredábamos fue el crédito que nos permitió conservar una fluida relación con John Murra y con los otros colegas de todas las nacionalidades que comparten la misma pasión por los Andes.

Agradecimientos: Agradezco Elizabeth Arkush por facilitarme su ponencia inédita "Pukaras de los Collas: Guerra y poder regional en la cuenca norte del Titicaca durante el Periodo Intermedio Tardío". Se agradecen las importantes sugerencias aportadas por los evaluadores.

\section{Referencias Citadas}

Amselle, J.L.

1999 [1990] Logiques Métisses: Anthropologie de l'Identité en Afrique et Ailleurs. Payot, Paris.

Arkush, E.

2009 Pukaras de los Collas: Guerra y poder regional en la cuenca norte del Titicaca durante el Periodo Intermedio Tardío. Presentado en el Taller Internacional de Arqueología del Noroeste Argentino y Andes Centro Sur, organizado por el Centro Regional de Estudios Arqueológicos (CREA)FHyCS-UNJu, 23-28 abril 2009. Manuscrito en posesión de la autora.
Barth, F.

1979 Los Grupos Étnicos y sus Fronteras. Fondo de Cultura Económica, México.

Boccara, G.

2005 Mundos nuevos en las fronteras del Nuevo Mundo. Nuevo Mundo Mundos Nuevos. Debates, 2001. 8 de febrero. $\mathrm{http} / /$ nuevomundo.revues.org/index426.html.

Bonfil Batalla, G.

1992 La teoría del control cultural en el estudio de procesos étnicos. En Identidad y Pluralismo Cultural en América Latina, editado por G. Bonfil Batalla, pp. 107-163. Universidad de Puerto Rico. CEHASS/ED, Buenos Aires. 
Boixadós, R.

1992 Informe de trabajo, Buenos Aires. Manuscrito en posesión de la autora.

1993 Pleitos por derechos a tierras, agua y mano de obra indígena en La Rioja colonial (1693-1712). Manuscrito en posesión de la autora.

Bouysse-Cassagne, Th.

1978 L'espace aymara: urco et uma. Annales Économies, Sociétés, Civilisations 33(5-6):1057-1080, Paris.

D'Altroy, T.

1987 Transitions in power: Centralization of Wanka political organization under Inka rule. Etnohistory 34:78-102.

del Río, M.

1989 Estructuración étnica Qhara-Qhara y su desarticulación colonial. Historia y Cultura 15:35-73. Sociedad Boliviana de Historia.

1990 Simbolismo y poder en Tapacarí. Revista Andina 8(1):77113. Centro Bartolomé de Las Casas, Cusco.

del Río, M. y A.M. Presta

1984 Un estudio etnohistórico en los corregimientos de Tomina y Yamparaes: casos de multietnicidad. Runa 14:220-246. Instituto de Ciencias Antropológicas, Facultad de Filosofía y Letras, Universidad de Buenos Aires, Buenos Aires.

Forte, R. y N. Silva Prada

2006 Cultura Política en América. Variaciones Regionales y Temporales. Universidad Autónoma Metropolitana, México.

Fuenzalida, F.

1967-1968 La matriz colonial de la comunidad indígena peruana: una hipótesis de trabajo. Revista del Museo Nacional 35:291-318. Lima.

Giudicelli, C.

2007 Encasillar la frontera. Clasificaciones coloniales y disciplinamiento del espacio en el área Diaguito-Calchaquí, siglos XVI-XVII. Anuario IEHS 22:161-212. Tandil.

Guevara Gil, J.A. y F. Salomon

1996 La visita personal de indios: ritual político y creación del "indio" en los Andes coloniales. Cuadernos de Investigación 1:5-48. Instituto Riva-Agüero, Pontificia Universidad Católica del Perú, Lima.

Hyslop, J.

1990 Inka Settlement Planning. University of Texas Press, Austin.

Lamana, G.

2008 Domination Without Dominance: Inca-Spanish Encounters in Early Colonial Peru. Duke University Press, Durham and London.

Lorandi, A.M.

1977 Arqueología y etnohistoria: hacia una visión totalizadora del Mundo Andino. En Obra del Centenario del Museo de La Plata, tomo II: 27-50. La Plata.

1978 Les horizons andines: critique d'un modele. Annales Économies, Sociétés, Civilisations 33(5-6):921-926.

1980 La frontera oriental del Tawantinsuyu: el Umasuyu y el Tucumán. Relaciones de la Sociedad Argentina de Antropología 14 (1):147-164. Buenos Aires.

1988 El servicio personal como agente de desestructuración en el Tucumán colonial. Revista Andina 6(1):135-173.

1998 [1988] Los diaguitas y el Tawantinsuyu. Una hipótesis de conflicto. En Las Fronteras del Estado Inca, editado por T.D. Dillehay y P.J. Netherly, pp. 198-216. Fundación Alexander Von Humboldt y ABYA-YALA, Quito.
1997 Introducción. El área andina meridional. En Tucumán Colonial y Charcas, compilado por A.M. Lorandi, pp. I: 15-74, Facultad de Filosofía y Letras, Universidad de Buenos Aires, Buenos Aires.

Lorandi, A.M. y R. Boixadós

1987-1988 Etnohistoria de los valles Calchaquíes en los siglos XVI y XVII. Runa, 17-18:227-424. Instituto de Ciencias Antropológicas, Facultad de Filosofía y Letras, Universidad de Buenos Aires.

2009 Sobre clasificaciones y descalificaciones. Una revisión crítica de "Etnohistoria de los valles Calchaquíes", veinte años después. Anuario de Estudios Históricos-Sociales 23. Universidad Nacional del Centro de la Provincia de Buenos Aires, en prensa.

Lorandi, A.M. y C. Bunster

1987-1988 Reflexiones sobre las categorías semánticas en las fuentes del Tucumán colonial. Runa 17-18:221-262. Instituto de Ciencias Antropológicas, Facultad de Filosofía y Letras, Universidad de Buenos Aires, Buenos Aires.

1990 Reflexiones sobre las categorías semánticas en las fuentes del Tucumán colonial (reimpreso con leves modificaciones) Histórica 14 (2):281-317. Pontificia Universidad Católica del Perú, Lima.

Lorandi, A.M., B. Cremonte y V. Williams

1991 Identificación étnica de los mitimaes instalados en el establecimiento incaico Potrero-Chaquiago. Actas del XI Congreso Nacional de Arqueología Chilena (1988), vol. 2, pp. 195-200. Santiago.

Morris, C. y D.E. Thompson

1985 Huánuco Pampa. An Inca City and its Hinterland. Thames and Hudson, London.

Murra, J.

1967 La visita de los chupachu como fuente etnológica. En Ortiz de Zúñiga, Iñigo Visitador, Visita de la Provincia de León de Huánuco en 1562, editado por J. Murra, pp. $383-$ 406. Universidad Nacional Herminio Valdizán, Huánuco. 1975 Formaciones Económicas y Políticas del Mundo Andino. IEP, Lima.

1978 La Organización Económica del Estado Inca. IEP, Lima.

Nacuzzi, L.

1998 Identidades Impuestas. Tehuelches, Aucas y Pampas en el Norte de la Patagonia. Sociedad Argentina de Antropología, Buenos Aires.

Presta, A.M.

1989 Mano de obra en una hacienda tarijeña en el siglo XVII: la Viña La Angostura. En Agricultura, Sociedad y Trabajo en América Hispana. Serie Nuevo Mundo: 5 siglos (3):43-60, editado por G. Izquierdo. Universidad de Chile, Universidad Católica de Valparaíso, Universidad Metropolitana, Embajada de España, Santiago.

Presta, A.M. y M. del Río

1993 Reflexiones sobre los churumatas del sur de Bolivia (siglos XVI-XVII). Memoria Americana 2:41-49. Sección Etnohistoria, Facultad de Filosofía y Letras, Universidad de Buenos Aires.

Renard-Cassevitz, F.M., T. Saignes y C. Taylor

1986 L'Inca, L'Espagnol et Les Sauvages. Tomo I. Editions Recherches sur les Civilisations, Paris.

Passeron, J.C. y J. Revel

2005 Penser par Cas. Editions de l'École des Hautes Études en Sciences Sociales, Paris. 
Platt, T.

1978 Symétries en miroir. Le concept de yanantin chez les Macha de Bolivie. Annales Économies, Sociétés, Civilisations 33(5-6):1081-1107.

Rodríguez, L.

2008 Después de las Desnaturalizaciones. Transformaciones Socio-Económicas y Étnicas en el Sur del Valle Calchaquí. Santa María, Fines del Siglo XVII-Fines del Siglo XVIII. Editorial Antropofagia, Buenos Aires.

Schaposchnik, A.

1991 ¿Cómo trabajamos con fuentes con escasos datos? Reflexión metodológica. Historia y Cultura 20:19-41. Sociedad Boliviana de Historia, Editorial Don Bosco, La Paz.

1995 Cuando Catamarca no era Catamarca. Etnohistoria de Colpes (siglos XVI y XVII). Ponencia presentada en las V Jornadas Interescuelas/Departamentos de Historia. Montevideo.
Sendón, $\mathrm{P}$.

2003 Cambio y la continuidad en las formas de organización social de las poblaciones rurales del sur peruano. El caso de la comunidad campesina de Phinaya. Debate Agrario. Análisis y Alternativas 36:1-13. Centro Peruano de Estudios Sociales, Lima.

Wachtel, N.

1997 Nota sobre el problema de las identidades colectivas en los Andes meridionales. En Homenaje a María Rostworowski, editado por R. Varón Gabai y J. Flores Espinoza, pp. 677 690. Instituto de Estudios Peruanos y Banco Central de Reserva del Perú, Lima.

Zanolli, C. y A.M. Lorandi

1995 Tributo y servicio personal en el Tucumán Colonial. Memoria Americana 4:91-104. Sección Etnohistoria, Facultad de Filosofía y Letras, Universidad de Buenos Aires.

2005 Tierra, Encomienda e Identidad: Omaguaca (1550-1638). Sociedad Argentina de Antropología, Buenos Aires.

\section{Notas}

1 Este trabajo se publicó originalmente con fecha de 1980, pero fue escrito en 1982 o 1983.

2 Sería imposible citar todos los trabajos de la última década. La lista completa y actualizada puede consultarse en www. seccionetnohistoria.com.ar

3 Son categorías de valor identificatorio de grandes poblaciones como los chunchos del oriente cuzqueño o los campas del oriente boliviano. No son designaciones étnicas.

4 Tomamos el término del título del libro de Lidia Nacuzzi (1998) aclarando que la autora no comparte la propuesta de aplicar los modelos de frontera a sociedades agropastoriles y semiurbanas.

5 Para comodidad del lector nos referiremos como "calchaquíes" a todos los pobladores de los valles Calchaquíes aunque en términos estrictos se trata de una población multiétnica.
6 En nuestro trabajo señalamos el ingreso de un reducido número de inmigrantes provenientes de zonas aledañas que buscaron refugio en los valles para escapar del dominio colonial.

7 La frontera sur del área pular estaba marcada en tiempos coloniales en la localidad de Atapsi y coincide con un fuerte incaico ubicado en sus proximidades, conocido como fuerte de Angastaco (Verónica Williams, información personal 2009).

8 AGI, Autos de Proceso a Pedro Bohorques, Charcas 58 y 126.

9 No haremos referencias actuales respecto al tema puesto que sólo nos interesa marcar que las precauciones metodológicas han sido expuestas en los Andes desde hace muchos años. 
